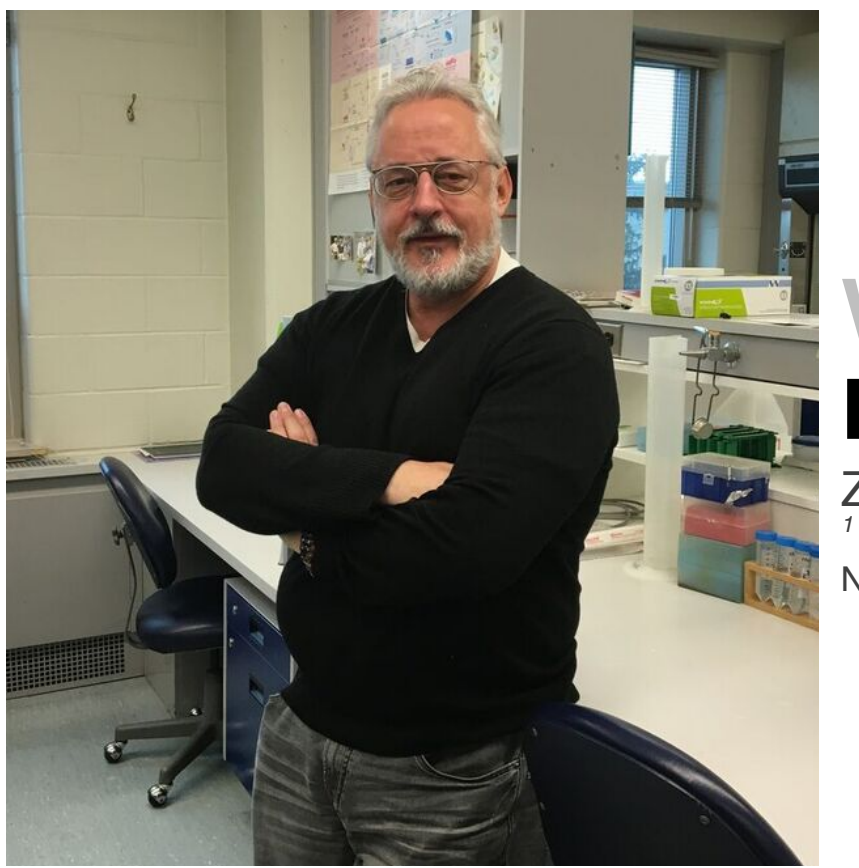

\section{The Scientific Industry}

Gilead Sciences, Amgen, Celgene, and Regeneron. Whether it's computer technology or applied biology, these companies all display one common goal: to employ and construct comprehensive think tanks composed of the best and brightest to drive innovation in human development. Dr. Kelly believes that the basis for success is teamwork; by "bringing individuals with different backgrounds and different levels of education to further elevate our understanding and development of treatments and cures for global issues". Not only should lab work be a healthy learning opportunity, it should also be set in an all- inclusive environment where everyone participating works together to contribute to a greater cause.

\section{The Purpose of Life}

Although individuals have different beliefs as to what their purpose in life is, Dr. Kelly's approach is simple: to become, through various levels of self-discovery, the best version of yourself as possible. From a purely biological standpoint, the purpose of life is to procreate and pass on one's genetic information to the next generation, but life itself is "complex, as we have two haploid cells [sperm and an egg] that combine via mostly still unknown processes, to form a viable lifeform capable of renewing the process when it reaches sexual maturity". The development of the embryo functions as a well-oiled machine, and to understand how this machine works is "our purpose as developmental biologists".

\section{Perseverance}

"Life is like a road with ditches on both sides, and never perfectly straight". Failure is a common theme amongst scientific experimentation, but to acknowledge our failures and "focus on what our end goals in life are, will push us forward to succeed". One of Dr. Kelly's roughest times in one of these "ditches" came while still a Postdoctoral Fellow, when the job market for Assistant Professor positions was bleak. Instead of going into industry, Dr.
Kelly persevered and continued to publish more research papers, all the while not giving up on the prospect of landing a position at a university. This patience and perseverance paid off and he was awarded his first position in the then Department of Zoology at Western. When asked why he persevered his response was simply, "we all have rough patches, but we must accept them, and this inevitably teaches us to become better individuals".

\section{Hobbies}

Aside from Dr. Kelly's investment within academia and research, he also partakes in numerous other pastimes. He expresses a strong interest in astronomy, photography, authoring fiction-fact stories, studying military history (especially World War I), as well as woodworking. Dr. Kelly has also mentioned that his father served in the Second World War, but his interest lies mainly in the First World War and his two Great Uncles that served in this conflict.

\section{Interest in Cell and Developmental Biology}

Biology is like a door with many keys, each of which can unlock a different perspective on the mysteries of life. Cell and Developmental biology is Dr. Kelly's field of expertise, and he believes that the key to discovering how multicellular organisms function is to first fully understand the complex operations within the single-celled, fertilized egg. The focus of his research pertains to how the embryo knows what to do and when to do it. For example, daughter cells may and probably do behave differently in new environments compared to their parents, even though they supposedly have the same genetic material. It's not quite that simple, but "it's almost like they have their own individuality before they even divide". Although we cannot explain all behaviours by attempting to translate the genetic code, we have learned that certain mutagenic and epigenetic effects produce specific cell behaviours. 


\section{Research Applications and Volunteering}

Amongst many applicants considered for research positions, only a few are admitted into their labs of choice. Some characteristics of an applicant that stands out from the rest is reiterated by Dr. Kelly as someone who is willing to "burn the midnight oil, and try their best to find a creative solution to the problem at hand". Throughout his supervisory experience, he has noticed that although some students have high cumulative GPAs, this does not necessarily translate into being a great problem solver. To succeed in any lab, one must always look at the problem from various perspectives. For example, Dr. Kelly mentions that a child who realizes the box protecting the gift is just as important as the gift itself is one who might be an ideal candidate at "thinkingout-of-the-box" problem-solving. As most can follow a protocol, those who "perfect" the protocol often rise to the top. Ultimately, those who use the scientific method to answer their biological question, and have the intrinsic and extrinsic motivation to work in a team situation, while continuing to ask questions and be humbled and amazed by unexpected results will eventually become our next generation of research scientists. Towards that end, many undergraduate students may find it difficult to obtain a research position upon first entry, but through volunteering at certain labs, these individuals will find themselves networking with Postdoctoral Fellows and other trainees, which will enhance their probability of obtaining future positions in the research community. One of the main things to be considered while looking for a volunteer position is the lab's productivity in this community, whether the research piques any interest within you, and the overall "healthiness" of the teamwork atmosphere of the lab.

\section{Tips for Success}

"Life is a game that everyone tries to win, although we may not necessarily win in all subjects, we are all cut out to do something significant in life". Those that treat their University experiences as a method of self-discovery, will excel in certain subjects because they will be productive, excited, and motivated within these areas. Ultimately, achieving a high GPA is not as important as finding what you love to do and working as hard as you can to keep that burning; the high GPA will easily follow.

\section{To Learn more on Dr. Kelly's lab and research, please visit his website at:}

http://publish.uwo.ca/ gkelly/home/ 